University of South Carolina

Scholar Commons

8-17-2011

\title{
Thermal Model for Lithium Ion Battery Pack with Mixed Parallel and Series Configuration
}

\author{
Meng Guo \\ Ralph E. White \\ University of South Carolina - Columbia, white@cec.sc.edu
}

Follow this and additional works at: https://scholarcommons.sc.edu/eche_facpub

Part of the Chemical Engineering Commons

\author{
Publication Info \\ Published in Journal of The Electrochemical Society, Volume 158, Issue 10, 2011, pages A1166-A1176. \\ (C) Journal of The Electrochemical Society 2011, The Electrochemcial Society. \\ (c) The Electrochemical Society, Inc. 2011. All rights reserved. Except as provided under U.S. copyright law, \\ this work may not be reproduced, resold, distributed, or modified without the express permission of The \\ Electrochemical Society (ECS). The archival version of this work was published in Journal of The \\ Electrochemical Society. \\ Publisher's Version: http://dx.doi.org/10.1149/1.3624836
}

This Article is brought to you by the Chemical Engineering, Department of at Scholar Commons. It has been accepted for inclusion in Faculty Publications by an authorized administrator of Scholar Commons. For more information, please contact digres@mailbox.sc.edu. 


\title{
Thermal Model for Lithium Ion Battery Pack with Mixed Parallel and Series Configuration
}

\author{
Meng Guo and Ralph E. White ${ }^{*, z}$ \\ Department of Chemical Engineering, University of South Carolina, Columbia, South Carolina 29208, USA
}

\begin{abstract}
In this work, a mathematical thermal model for lithium ion battery pack with specific configuration was developed by coupling the single particle model and energy balance equation with basic circuit constraints. The temperature variation at different parts of the battery pack was considered in charge/discharge operations, and the dependency of cell parameters on temperature were taken into account. The model was validated by comparing the simulated current, voltage, and temperature profiles with experimental data. Case studies such as battery balancing and circuit interruption were also performed and discussed. (C) 2011 The Electrochemical Society. [DOI: 10.1149/1.3624836] All rights reserved.
\end{abstract}

Manuscript submitted November 23, 2010; revised manuscript received June 13, 2011. Published August 17, 2011.

Today, rechargeable lithium ion battery packs are widely used in the space industry as energy storage devices for satellites and other space vehicles. ${ }^{1}$ The primary role of lithium ion battery packs in these crafts is to provide power when the Earth's shadow blocks the satellite's exposure to the sun. In the practical application of lithium ion battery packs, the battery performances, such as the voltage, power, capacity, and life, are all strongly affected by the temperature conditions. So thermal studies about battery packs including several lithium ion cells have become of increasing significance during recent years.

In recent years, a variety of thermal models for single lithium ion cells have been developed. ${ }^{2-6}$ In those studies, the electrochemical models ${ }^{7-9}$ of Li-ion cell were coupled with energy balance and heat transfer equations, ${ }^{10,11}$ and the transport and kinetic parameters were also usually considered as dependent on cell temperature. ${ }^{12-16}$ In 2000, Gu and Wang ${ }^{17}$ developed a thermal-electrochemical coupled model for $\mathrm{Li}_{\mathrm{y}} \mathrm{Mn}_{2} \mathrm{O}_{4}$ and carbon battery system, in which the porous electrode model was coupled with the energy balance equation. In 2008, Kumaresan et al. ${ }^{6}$ applied Wang's model equations to simulate the rate discharge behaviors of $\mathrm{LiCoO}_{2}$ and MCMB pouch cells at different temperature, and the model showed very good fit to the experimental data. In the most recent work of Ref. 2, the single particle model was used to develop a more simplified thermal model, and this thermal model has great agreements with both Kumaresan's model ${ }^{6}$ and the experimental data.

Our work is focused on the electrical and thermal behaviors of a satellite battery pack built with twenty-four cells connected in a mixed parallel and series configuration. The model was developed by coupling the single particle thermal models for individual cells with circuit constraints. The model predictions were validated by comparing the simulation results with experimental data.

\section{Experimental}

The experimental battery pack consists of 24 MSA prismatic cells. Each cell is made up of a MCMB anode (negative electrode) and $\mathrm{LiCoO}_{2}$ cathode (positive electrode), and the nameplate capacity for this type of cell is $12.5 \mathrm{Ah}$. The 24 single cells are connected as the circuit diagram shown in Fig. 1: three cells are connected in parallel to form a cell module called "virtual cell", and eight virtual cells are connected in series to build the battery pack. For the readers' convenience, in this work, the virtual cells are numbered from 1 to 8 and the single cells in each virtual cell are marked as $a, b$ and $c$; for example, a cell labeled as "cell 3 - $a$ " refers to the first single cell in the third virtual cell.

The schematic configuration for the actual battery set-up is shown in Fig. 2. Each single cell in this battery is wrapped by kapton tape, and all three single cells in each virtual cell are closely packed together. Virtual cells are embedded in the holders called

\footnotetext{
* Electrochemical Society Fellow.

${ }^{\mathrm{z}}$ E-mail:white@cec.sc.edu
}

L-brackets, and each L-bracket has a horizontal board seating under the virtual cell and a vertical board standing at the edge of the virtual cell.

The thermal condition for this battery pack is shown in Fig. 3 . The left, right, front, rear, and top facets of the battery pack and the space between the two rows of cells are all covered by thermal insulating material. The battery pack is placed on a cold plate set at a constant temperature of $15^{\circ} \mathrm{C}$. Thermal couples are placed on the surface of cells marked with "*” in Fig. 2.

\section{Mathematical Model}

Assumptions.-The basic assumptions for developing this battery thermal model are stated below.

(1) The single particle model, in which the porous electrode is represented by a number of identical spherical single particles, can be used to describe the mass balance in each cell. According the experimental protocols, this battery pack is operated below $1 \mathrm{C}(37.5$ A) rate in the cycling tests, and as discussed in Ref. 7, the single particle shows very good accuracy at such low rates because the solid phase diffusion process is the limiting factor. Reference 2 also shows that the single particle model including energy balance has great agreements with both experimental data and porous electrode model at current rate lower or equal to $1 \mathrm{C}$. Therefore, the discussion results from Refs. 2 and 7 strongly support that the single particle model is safe to be used in our simulation cases.

(2) In this battery pack, the single prismatic cells (including the kapton film) are assumed to be isothermal bodies in which the spatial temperature distribution can be neglected, so the temperature of each cell is regarded as a state variable which only varies with time.

(3) According to the surrounding thermal conditions shown in Fig. 3, the heat fluxes are zero on the boundaries which are thermal insulation. The heat generated inside the battery pack during charge/ discharge operations will be taken away by the cold plate operated at constant temperature, so the temperature of the cold plate is regarded as the ambient temperature $T_{a m b}$.

(4) Each L-bracket holding the virtual cells is split into two parts: a vertical board standing between virtual cells and a horizontal board sitting between cells and cold plate (Fig. 4). As shown in Fig. 4 , there are nine boards in total (five vertical boards and four horizontal boards), and each of these boards is assumed to be isothermal. For convenience, these boards are labeled as $b 1$ through $b 9$. In this model, the L-bracket boards are regarded as boundaries in heat transfer, that is, the heat accumulation on these boards is neglected and the total input heat flux equals to the total output heat flux on each board.

(5) The heat transfer between different isothermal parts (cells or L-bracket boards) follows the Fourier's law of conduction.

(6) All the cells in the battery pack are built with the same weight and geometric size; the cell-to-cell difference in certain 


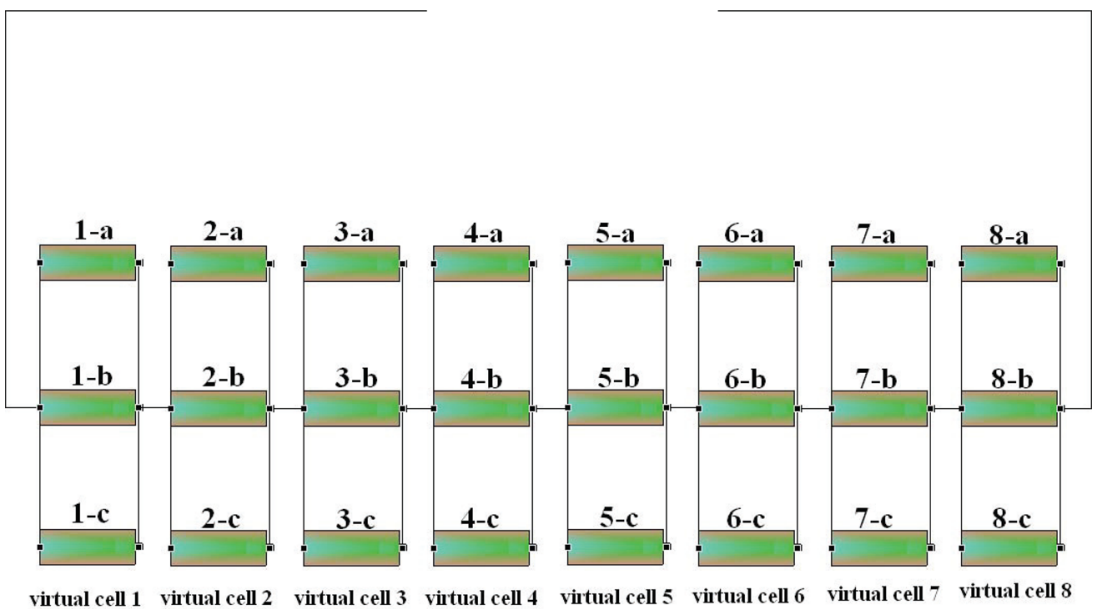

Figure 1. (Color online) The circuit diagram for the experimental battery.

design parameters such as the particle radius, electrode surface area and specific heat capacity is neglected.

(7) The ohm resistance of cell $\left(R_{\text {cell }}\right)$ includes the resistance for solution phase charge transfer in the cell and the contact resistance between cell terminals and connectors. ${ }^{2}$ The values of $R_{\text {cell }}$ may vary between different cells due to temperature differences or hardware connections, therefore, the slight difference in the $R_{\text {cell }}$ between cells would be considered.

Solid phase diffusion.-According to Ref. 7, in the single particle model, each electrode of a single cell can be represented by a single spherical particle whose area is equivalent to that of the active area of the solid phase in the porous electrode. The mass balance in the spherical particle of electrode $j$ (where $j=p, n$ ) can be described by the following governing equations

$$
\begin{gathered}
\frac{\partial \bar{c}_{1, j}}{\partial t}+\frac{15 D_{1, j}}{R_{j}^{2}}\left(\bar{c}_{1, j}-c_{s, j}\right)=0 \\
\frac{5 D_{1, j}}{R_{j}}\left(c_{s, j}-\bar{c}_{1, j}\right)+\frac{J_{j}}{A_{j} F}=0
\end{gathered}
$$

where $\bar{c}_{1, j}$ denotes the average particle concentration of lithium in electrode $j, c_{s, j}$ denotes the concentration of lithium at the particle surface of electrode $j, R_{j}$ denotes particle radius of electrode $j, D_{1, j}$ denotes the diffusion coefficient of lithium inside the particle of electrode $j, A_{j}$ denotes the electroactive surface area of electrode $j, J_{j}$ denotes the current for intercalation reaction of electrode $j, t$ denotes time, and $F$ denotes the Faraday's constant. The electrode surface state-of-charge (SoC) is defined as

$$
\theta_{j}=c_{s, j} / c_{1, j}^{\max }
$$

where $\theta_{j}$ denotes the state-of-charge for electrode $j$, and $c_{1, j}^{\max }$ denotes the maximum lithium concentration in the particle of electrode $j$. The surface SoC is usually regarded as the dimensionless concentration of lithium at particle surface, and the value of surface SoC ranges from 0 to 1 .

The Butler-Volmer equation.-The lithium intercalation reaction for $\mathrm{LiCoO}_{2}$ and carbon electrodes are written as

$$
\mathrm{CoO}_{2}+\mathrm{Li}+\mathrm{e}-\underset{\text { discharge }}{\stackrel{\text { charge }}{\leftrightarrows}} \mathrm{LiCoO}_{2}
$$

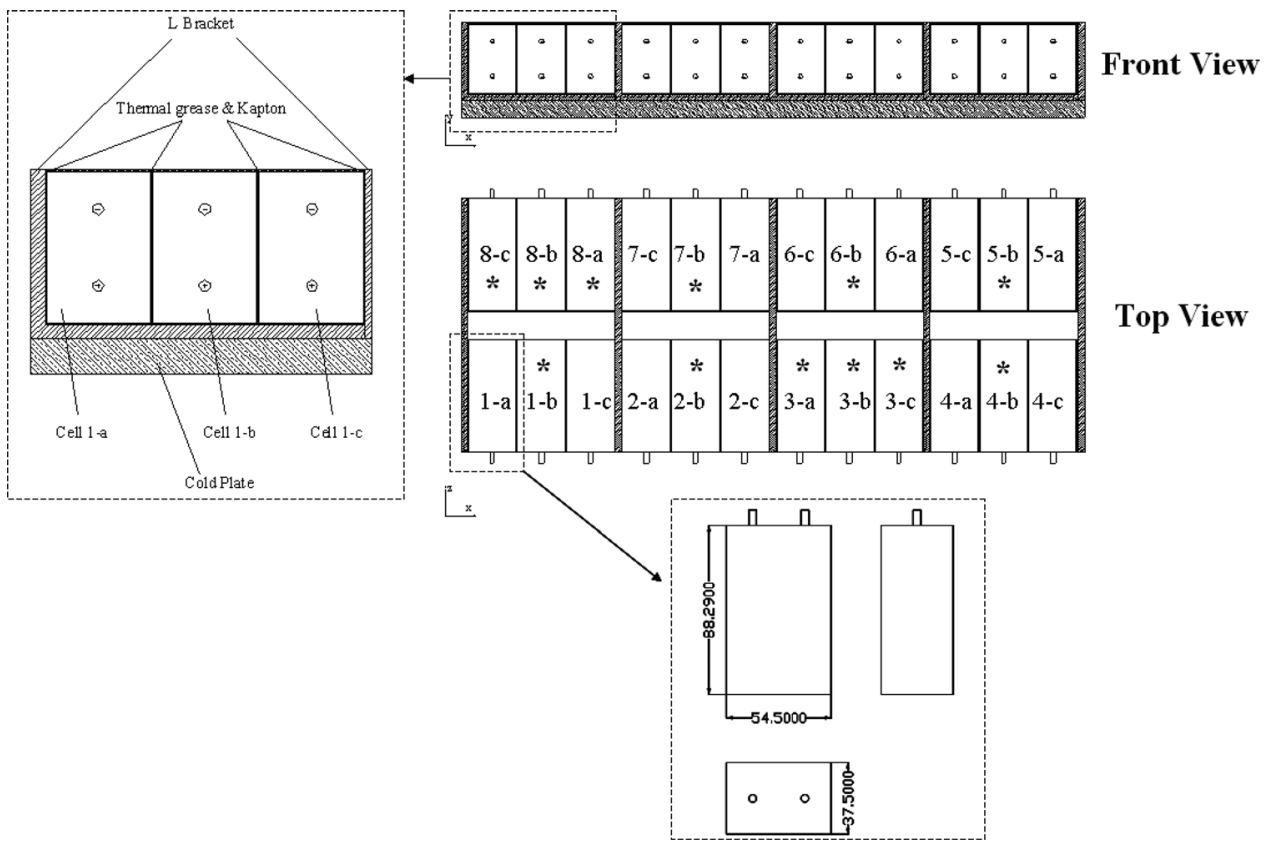

Figure 2. The experimental set up for 8 s3p battery pack, where "*" means the temperature of that cell is recorded. 


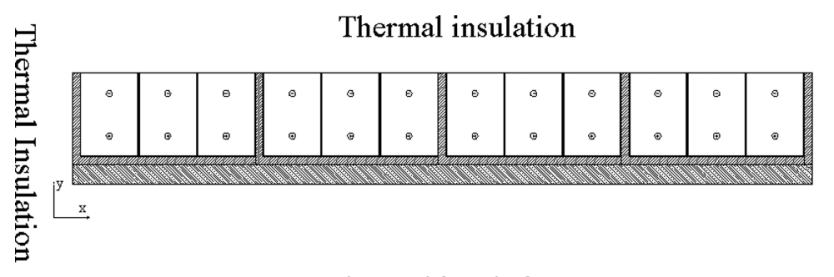

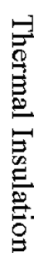

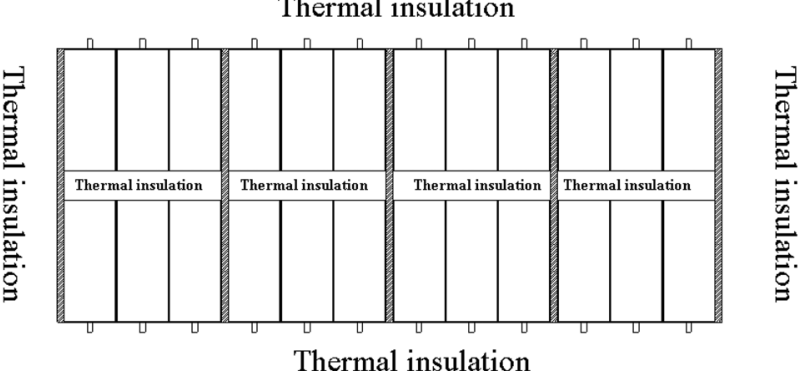

Figure 3. The heat transfer condition for the experimental battery pack.

$$
\mathrm{Li}+\mathrm{C}_{6}+\mathrm{e}^{-} \underset{\text { charge }}{\stackrel{\text { discharge }}{\leftrightarrows}} \mathrm{LiC}_{6}
$$

The reaction kinectcs for the lithium intercalation is described by the Butler-Volmer equations

$$
\begin{gathered}
J_{j}-A_{j} k_{j} F\left(c_{1, j}^{\max }-c_{s, j}\right)^{1 / 2} c_{s / j}^{1 / 2} c_{2}^{1 / 2}\left\{\exp \left(\frac{\alpha_{a, j} F}{R T} \eta_{j}\right)\right. \\
\left.-\exp \left(\frac{\alpha_{c, j} F}{R T} \eta_{j}\right)\right\}=0
\end{gathered}
$$

where $k_{j}$ denotes the rate constant for electrochemical reaction of electrode $j, \eta_{j}$ denotes the overpotential of electrode $j, \alpha_{a, j}$ denotes the anodic transfer coefficient of electrode $j, \alpha_{c, j}$ denotes the cathodic transfer coefficient of electrode $j, c_{2}$ denotes the electrolyte concentration in the solution phase, and $R$ denotes the universal gas constant. The overpotential of electrode $j$ is expressed as

$$
\eta_{j}=\phi_{1, j}-\phi_{2}-U_{j}^{\theta}
$$

where $\phi_{1, j}$ denotes the solid phase potential of electrode $j, \phi_{2}$ denotes the solution phase potential, and $U_{j}^{\theta}$ denotes the open circuit potential (OCP) of electrode $j$. The cell voltage is defined as

$$
V_{\text {cell }}=\phi_{1, p}-\phi_{1, n}+I R_{\text {cell }}
$$

where $V_{\text {cell }}$ denotes the cell voltage, $R_{\text {cell }}$ denotes the ohm resistance of cell, and $I$ denotes the applied current of cell. In this work, applied current $I$ is defined as positive for charge and negative for discharge. The correlation between $I$ and $J_{j}$ is as follow

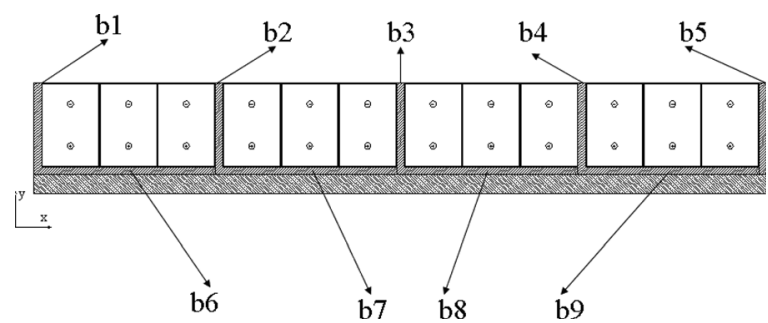

Figure 4. The label of boards on L-brackets.

$$
\begin{gathered}
I=J_{j}(\text { where } j=p) \\
I=-J_{j}(\text { where } j=n)
\end{gathered}
$$

When the applied current $I=0$, the open circuit voltage (OCV) of cell equals to the $\mathrm{OCP}$ difference between positive and negative electrodes

$$
\Delta U=\left.V_{\text {cell }}\right|_{I=0}=U_{p}^{\theta}-U_{n}^{\theta}
$$

where $\Delta U$ denotes the OCV of cell.

The energy balance.-According to Ref. 10, the energy balance of a cell can be written as

$$
\rho \nu C_{p} \frac{d T}{d t}=I T\left(\frac{\partial U_{p}^{\theta}}{\partial T}-\frac{\partial U_{n}^{\theta}}{\partial T}\right)+I\left[V_{\text {cell }}-\left(U_{p}^{\theta}-U_{n}^{\theta}\right)\right]-q
$$

where $\rho$ denotes the density of cell, $v$ denotes the volume of cell, $C_{p}$ denotes the specific heat capacity of cell, the partial derivative of electrode OCP with temperature $\left(\frac{\partial U_{j}^{\theta}}{\partial T}\right)$ is the entropy change coefficient for the electrochemical reaction of electrode $j$, and $q$ is the heat flow rate from single cell to surroundings. In Eq. 12, the term $I T\left(\frac{\partial U_{p}^{\theta}}{\partial T}-\frac{\partial U_{n}^{\theta}}{\partial T}\right)$ is usually known as the reversible heat which is caused by the entropy change of electrochemical reactions. The term $I\left[V_{\text {cell }}-\left(U_{p}^{\theta}-U_{n}^{\theta}\right)\right]$ is usually known as the irreversible heat which is generated from electrode polarization. The heat transfer term is calculated as

$$
q=\sum_{k} N_{k} S_{k}
$$

where $N_{k}$ denotes the heat flux on the $k$ th facet of cell, $S_{k}$ denotes the area of the $k$ th facet of the cell.

With the intensive-property representation for Fourier's law of conduction, the heat flow can be reformulated generally as

$$
\text { Heat Flow }=\frac{\text { Temperature Difference Between Bodies }}{\text { Thermal Resistance }}
$$

According to assumption (2) and (4), single cells, L-bracket boards, and the cold plate are all isothermal bodies, so we have five types of contact thermal resistance between different bodies (see Table I). The values for these types of thermal resistance are estimated by comparing the simulated temperature curves with experimental data. The heat flow rate between any two different isothermal bodies can be calculated as the temperature difference divided by the contact thermal resistance between these two bodies. To clarify the above discussions, we take cell 1- $a$ as an example. A plot for this cell and its ambient surroundings is presented in Fig. 5. According to Fig. 5, facets 2, 5 and 6 of cell $1-a$ are thermal insulated, so that the heat flux on these boundaries is zero

$$
\begin{aligned}
& N_{2}=0 \\
& N_{5}=0
\end{aligned}
$$

Table I. The different types of thermal resistance used in this thermal model.

\begin{tabular}{lcc} 
Interface & $\begin{array}{c}\text { Symbol for contact } \\
\text { thermal resistance }\end{array}$ & Unit \\
\hline Cell/vertical board & $R_{h, C V}$ & $(\mathrm{~K} / \mathrm{w})$ \\
Cell/horizontal board & $R_{h, C H}$ & $(\mathrm{~K} / \mathrm{w})$ \\
Cell/cell & $R_{h, C C}$ & $(\mathrm{~K} / \mathrm{w})$ \\
Vertical board/horizontal board & $R_{h, V H}$ & $(\mathrm{~K} / \mathrm{w})$ \\
Horizontal board/cold plate & $R_{h, H P}$ & $(\mathrm{~K} / \mathrm{w})$
\end{tabular}




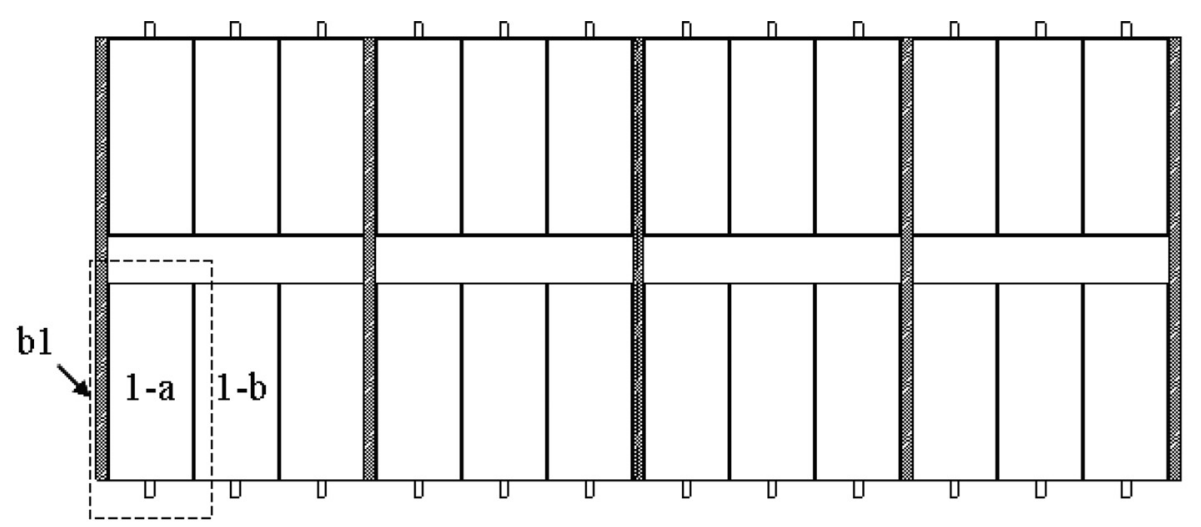

Surface 2: Thermal insulation

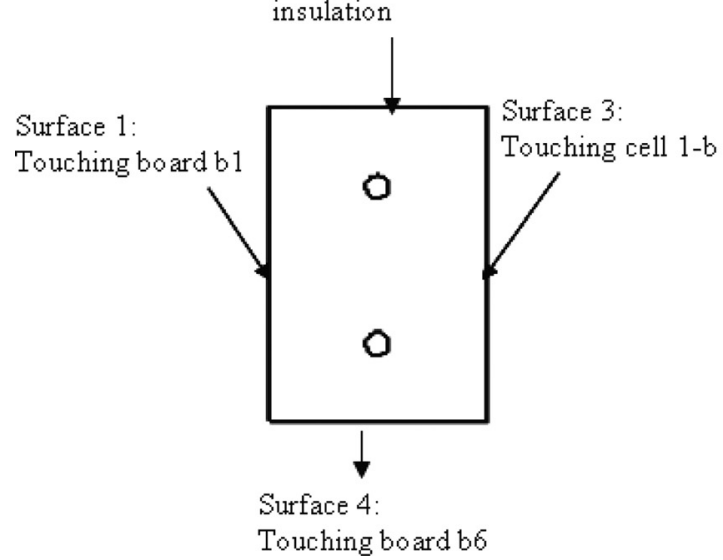

Surface 5: Thermal

Surface 6: Thermal insulation

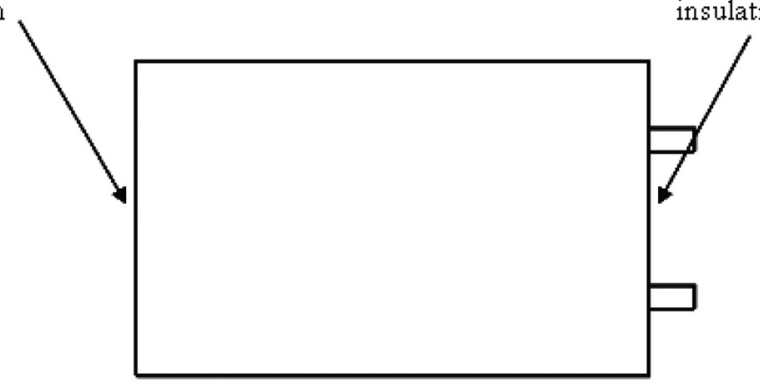
insulation

Figure 5. The plot for cell 4-c and its ambient surroundings.

$$
N_{6}=0
$$

Facet 1 of cell $1-a$ is contacted with L-bracket board $b 1$, and the total heat flow rate on this surface is expressed as

$$
N_{1} S_{1}=\frac{T_{1-a}-T_{b 1}}{R_{h, C V}}
$$

where $T_{1-a}$ denotes the temperature of cell 1- $a$ and $T_{b 1}$ denotes the temperature of board $b 1$. Facet 3 of cell $1-a$ is contacted with cell $1-b$, so the total heat flow rate on this boundary is

$$
N_{3} S_{3}=\frac{T_{1-a}-T_{1-b}}{R_{h, C C}}
$$

Facet 4 of cell 1- $a$ is contacted with L-bracket board $b 6$, so the total heat flow rate on this boundary is

$$
N_{4} S_{4}=\frac{T_{1-a}-T_{b 6}}{R_{h, C H}}
$$

From Eqs. 13 through 20, the total heat flow rate on cell 1-a is calculated as

$$
q_{1-a}=\frac{T_{1-a}-T_{b 1}}{R_{h, C V}}+\frac{T_{1-a}-T_{1-b}}{R_{h, C C}}+\frac{T_{1-a}-T_{b 6}}{R_{h, C H}}
$$

According to assumption (4), the energy balance on an L-bracket board is expressed as

$$
q^{\prime}=\sum_{k} N_{k} S_{k}=0
$$

where $q^{\prime}$ denotes the heat flow rate between a board and its surroundings.

The temperature dependency of parameters.-Several parameters in this model are functions of temperature. The solid phase diffusion coefficients and the electrochemical reaction rate constants are dependent on temperature through the Arrhenius correlation ${ }^{2,11}$

$$
\begin{gathered}
D_{1, j}=D_{1, j, r e f} \exp \left[\frac{E a_{d, j}}{R}\left(\frac{1}{T}-\frac{1}{T_{r e f}}\right)\right] \\
k_{j}=k_{j, r e f} \exp \left[\frac{E a_{r, j}}{R}\left(\frac{1}{T}-\frac{1}{T_{r e f}}\right)\right] \\
(j=p, n)
\end{gathered}
$$

where $T_{\text {ref }}$ denotes the reference temperature which is set for $25^{\circ} \mathrm{C}$, $D_{1, j, r e f}$ denotes the diffusion coefficient of lithium in the particle of electrode $j$ at reference temperature, $k_{j, r e f}$ denotes the rate constant for the electrochemical reaction of electrode $j$ at reference temperature, $E_{a d, j}$ denotes the activation energy for the lithium diffusion in the particle of electrode $j, E_{a r, j}$ denotes the activation energy for the electrochemical reaction of electrode $j$. The dependency of open circuit potential on cell temperature can be approximated using Taylor's expansion

$$
\begin{gathered}
U_{j}^{\theta}=U_{j, r e f}^{\theta}+\frac{\partial U_{j}^{\theta}}{\partial T}\left(T-T_{r e f}\right) \\
(j=p, n)
\end{gathered}
$$

where $U_{j, r e f}^{\theta}$ denotes the open circuit potential of electrode $j$ at reference temperature. $U_{j, r e f}^{\theta}$ and $\frac{\partial U_{j}^{\theta}}{\partial T}$ are functions of electrode surface $\mathrm{SoC}$, and the correlations are presented in Appendix A. 
The V-I correlation.-According to the circuit diagram in Fig. 1, the current and voltage of cells in should follow certain basic laws of electrical circuit:

(1) in each virtual, the three single cells connected in parallel cell must have the same voltage all the time

$$
\begin{gathered}
V_{\text {cell }, 1-a}=V_{\text {cell }, 1-b}=V_{\text {cell }, 1-c} \\
V_{\text {cell }, 2-a}=V_{\text {cell }, 2-b}=V_{\text {cell }, 2-c} \\
\ldots \ldots \\
V_{\text {cell, }, 8-a}=V_{\text {cell }, 8-b}=V_{\text {cell }, 8-c}
\end{gathered}
$$

(2) the total current on a virtual cell equals to the sum of current passing individual cells;

(3) all the virtual cells connected in series are of the same current all the time

$$
I_{1-a}+I_{1-b}+I_{1-c}=I_{2-a}+I_{2-b}+I_{2-c}=\ldots=I_{8-a}+I_{8-b}+I_{8-c}
$$

For the current control operation, the current of cells follows

$$
\begin{aligned}
I_{1-a}+I_{1-b}+I_{1-c} & =I_{2-a}+I_{2-b}+I_{2-c}=\ldots .=I_{8-a}+I_{8-b}+I_{8-c} \\
& =I_{a p p}
\end{aligned}
$$

where $I_{a p p}$ denotes the applied current on the battery pack. For the voltage control operation, the voltage of cells follows

$$
\sum_{k=1}^{8} V_{c e l l, k-\delta}=V_{a p p}
$$

where $V_{a p p}$ denotes the applied voltage on the battery pack, and the subscript $\delta$ denotes label of individual cells in the $k$ th virtual cell which can be either $a, b$, or $c$.

Model simulation.-The flowsheet for model simulation procedures are shown in Fig. 6. The initial conditions include the average particle concentration of lithium in positive/negative electrode and the temperature for individual cells. At the initial time, the OCV of cells connected in parallel must follow the circuit law in Eq. 26, and

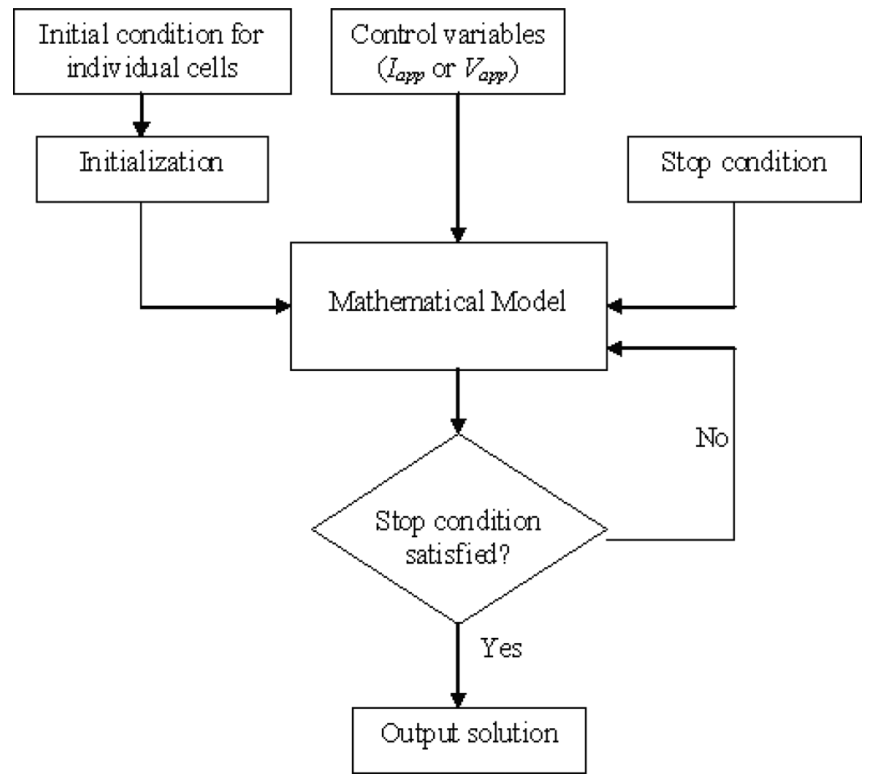

Figure 6. The flowsheet for simulation process of this model. due to this additional constraint, the initial values for lithium concentration in different cells are not independent variables. An initialization step called the self-balancing step is used to obtain the consistent initial values which satisfy the OCV constraint for parallel circuit before starting simulation. The details of this initialization step are seen in Appendix B. The control variables (ie, $I_{a p p}$ or $V_{a p p}$ ) are also inputs to run the model. The stop condition includes the end of charge/discharge voltage for constant current process or cut off current for constant voltage process.

As the cell voltage may drop rapidly at the end of discharge, the backward differentiate formula (DBF) method, which ensures sufficient accuracy for the solution of stiff nonlinear differential-algebraic-equations (DAE) system, was chosen to solve this model. The simulation procedures including the input of initial values, coding of model equations, and process of solutions were controlled by MATLAB. A FORTRAN package "Differential Algebraic System Solver" (DASSL), which is compatible with MATLAB and able to determine step length automatically, was called in solving the DAE system.

\section{Results and Discussion}

The values of transport and kinetic parameters for electrode active materials, such as the diffusion coefficients, reaction rate constants, and activation energy are found in the literature. ${ }^{2,6,7}$ The values for cell design parameters, such as the cell geometry dimensions, the electroactive surface area of electrodes, and the cell density, are provided by our sponsors and the cell manufacturer. These constant parameter values are obtained from the references listed in Table II.

Simulation for battery self-balancing.- To simulate the self-balancing process, we assumed that the positive electrode surface SoC values $\left(\theta_{p}\right)$ for the 24 unconnected individual cells are uniformly distributed between 0.985 and 0.995 , and the negative electrode sur-

\begin{tabular}{|c|c|c|c|}
\hline & $j=p$ & $j=n$ & Unit \\
\hline $\mathrm{A}_{j}$ & 7.92 & 5.73 & $\mathrm{~m}^{2}$ \\
\hline$c_{1, j}^{\max }$ & $51410^{\mathrm{a}, \mathrm{b}}$ & $31833^{\mathrm{a}, \mathrm{b}}$ & $\mathrm{mol} \cdot \mathrm{m}^{-3}$ \\
\hline$D_{1, j, r e f}$ & $3.9 \times 10^{-14 a, g}$ & $1.0 \times 10^{-14 \mathrm{a}, \mathrm{g}}$ & $\mathrm{m}^{2} / \mathrm{s}$ \\
\hline$E a_{d, j}$ & $2.9 \times 10^{4 c}$ & $3.50 \times 10^{4 \mathrm{e}}$ & $\mathrm{J} / \mathrm{mol}$ \\
\hline$E a_{r, j}$ & $5.8 \times 10^{4 \mathrm{f}}$ & $2.0 \times 10^{4 \mathrm{~d}}$ & $\mathrm{~J} / \mathrm{mol}$ \\
\hline$k_{j, r e f}$ & $6.6667 \times 10^{-11 a, b}$ & $1.764 \times 10^{-11 \mathrm{a}, \mathrm{b}}$ & $\mathrm{m}^{2.5} \cdot \mathrm{mol}^{-0.5} \cdot \mathrm{s}^{-1}$ \\
\hline$R j$ & $8.5 \times 10^{-6}$ & $12.5 \times 10^{-6}$ & $\mathrm{~m}$ \\
\hline$\alpha_{a, j}$ & 0.5 & 0.5 & \\
\hline$\alpha_{c, j}$ & 0.5 & 0.5 & \\
\hline$c 2$ & \multicolumn{2}{|c|}{1000} & $\mathrm{~mol} \cdot \mathrm{m}^{-3}$ \\
\hline$C_{p}$ & \multicolumn{2}{|c|}{577} & $\mathrm{~J} \cdot \mathrm{kg}^{-1} \cdot \mathrm{K}^{-1}$ \\
\hline$F$ & \multicolumn{2}{|c|}{96487} & $\mathrm{C} / \mathrm{mol}$ \\
\hline$R$ & \multicolumn{2}{|c|}{8.314} & $\mathrm{~J} \cdot \mathrm{mol}^{-1} \cdot \mathrm{K}^{-1}$ \\
\hline$T_{r e f}$ & \multicolumn{2}{|c|}{25} & ${ }^{\circ} \mathrm{C}$ \\
\hline$v$ & \multirow{2}{*}{\multicolumn{2}{|c|}{$\begin{array}{c}0.08829 \times 0.0545 \times 0.0375 \\
4.49 \times 10^{3}\end{array}$}} & $\mathrm{~m}^{3}$ \\
\hline$\rho$ & & & $\mathrm{kg} \cdot \mathrm{m}^{-3}$ \\
\hline
\end{tabular}
face $\operatorname{SoC}\left(\theta_{n}\right)$ are uniformly distributed between 0.005 and 0.015 . By the methods described in Appendix B, we obtained the values for individual electrode surface $\mathrm{SoC}$ after the self-balancing of cells. The standard deviations of surface SoC before and after the self-balancing are presented in Fig. 7. According to Figs. $7 \mathrm{a}$ and $7 \mathrm{~b}$, the

Table II. The constant parameter values used in the model.

${ }^{a}$ Reference 2 .

${ }^{\mathrm{b}}$ Reference 6 .

${ }^{\mathrm{c}}$ Reference 13.

${ }^{\mathrm{d}}$ Reference 14.

${ }^{\mathrm{e}}$ Reference 15.

${ }^{\mathrm{f}}$ Reference 16.

${ }^{\mathrm{g}}$ Reference 18. 


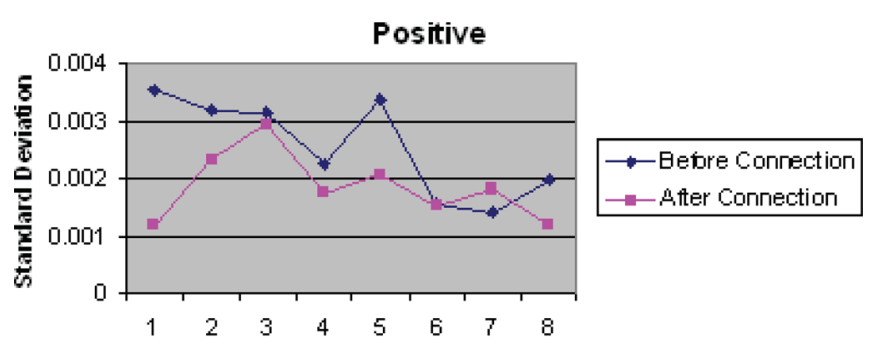

(a)

Virtual Cell Inclex

Negative
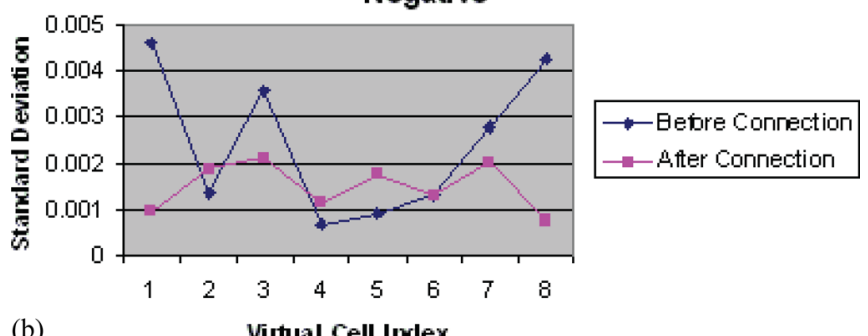

(b)

Virtual Cell Index

Positive-Negative

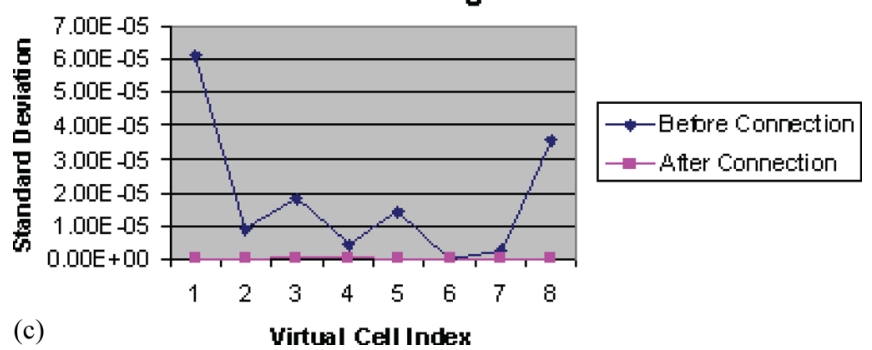

Figure 7. (Color online) The change of standard deviation for the (a) positive electrode surface $\mathrm{SoC}$ (b) negative electrode surface $\mathrm{SoC}$ (c) the surface SoC difference between positive and negative electrode during the self-balancing process.

self-balancing does not cause significant decrease in the standard deviations of surface SoC for individual electrodes $\left(\sigma_{\theta, j}\right.$, where $j=p, n)$, and the values of $\sigma_{\theta, j}$ in some virtual cells even increase after cells being connected. In Fig. 7c, however, the standard deviation for the difference between positive electrode surface $\mathrm{SoC}$ and negative electrode surface SoC, $\sigma_{\theta_{p}-\theta_{n}}$, is found to decrease dramatically for all virtual cells after the self-balancing.

The reason for the phenomena described above can be explained by the sensitivity analysis. The OCV of cell $i$ can be linearized when the change in electrode surface SoC is not large

$$
\Delta U_{i} \approx C+\lambda_{p} \theta_{p, i}-\lambda_{n} \theta_{n, i}
$$

where $\lambda_{p}=\partial U_{p}^{\theta} / \partial \theta_{p}, \lambda_{n}=\partial U_{n}^{\theta} / \partial \theta_{n}$, and $C$ is a constant. According to Fig. A-1, both $\lambda_{p}$ and $\lambda_{n}$ are negative. The average OCV of $N$ cells can be expressed as

$$
\Delta \bar{U}=\frac{1}{N} \sum_{i=1}^{N} \Delta U_{i}=C+\lambda_{p} \bar{\theta}_{p}-\lambda_{n} \bar{\theta}_{n}
$$

so the standard deviation of cell OCV is calculated as

$$
\begin{aligned}
\sigma_{\Delta U}^{2} & =\frac{1}{N} \sum_{i=1}^{N}\left(\Delta U_{i}-\Delta \bar{U}\right)^{2} \\
& =\frac{1}{N} \sum_{i=1}^{N}\left[\lambda_{p}\left(\theta_{p, i}-\bar{\theta}_{p}\right)-\lambda_{p}\left(\theta_{n, i}-\bar{\theta}_{n}\right)\right]^{2}
\end{aligned}
$$

substitute Eq. 30 into 32 to obtain

$$
\begin{aligned}
\sigma_{\Delta U}^{2}= & \frac{\lambda_{p}^{2}}{N} \sum_{i=1}^{N}\left(\theta_{p}-\bar{\theta}_{n}\right)^{2}-\frac{2 \lambda_{p} \lambda_{n}}{N} \sum_{i=1}^{N}\left(\theta_{p}-\bar{\theta}_{p}\right)\left(\theta_{n}-\bar{\theta}_{n}\right) \\
& +\frac{\lambda_{n}^{2}}{N} \sum_{i=1}^{N}\left(\theta_{n}-\bar{\theta}_{n}\right)^{2} \Rightarrow \sigma_{\Delta U}^{2}=\left(\lambda_{p}^{2}-\lambda_{p} \lambda_{n}\right) \sigma_{\theta, p}^{2} \\
& +\lambda_{p} \lambda_{n} \sigma_{\theta_{p}-\theta_{n}}^{2}+\left(\lambda_{n}^{2}-\lambda_{p} \lambda_{n}\right) \sigma_{\theta, n}^{2}
\end{aligned}
$$

According to Eq. 33, the sensitivity of $\sigma_{\Delta U}^{2}$ with $\sigma_{\theta_{p}-\theta_{n}}^{2}$ is

$$
\frac{\partial \sigma_{\Delta U}^{2}}{\partial \sigma_{\theta_{p}-\theta_{n}}^{2}}=\lambda_{p} \lambda_{n}
$$

As discussed above, $\lambda_{p}$ and $\lambda_{n}$ are both negative, so

$$
\frac{\partial \sigma_{\Delta U}^{2}}{\partial \sigma_{\theta_{p}-\theta_{n}}^{2}}>0
$$

In self-balancing, $\sigma_{\Delta U}^{2}$ drops to zero, and Eq. 35 indicates that $\sigma_{\theta_{p}-\theta_{n}}^{2}$ must decrease accordingly. The other sensitivities $\partial \sigma_{\Delta U}^{2} / \partial \sigma_{\theta, p}^{2}=\left(\lambda_{p}^{2}-\lambda_{p} \lambda_{n}\right)$ and $\partial \sigma_{\Delta U}^{2} / \partial \sigma_{\theta, n}^{2}=\left(\lambda_{n}^{2}-\lambda_{p} \lambda_{n}\right)$ are not always positive or negative, so $\sigma_{\theta, p}^{2}$ and $\sigma_{\theta, n}^{2}$ can either decrease or increase during self-balancing.

In our model, the simulation for battery self-balancing is an initialization step to obtain consistent initial surface SoC values for cells. Besides the mathematical significance, battery balancing is
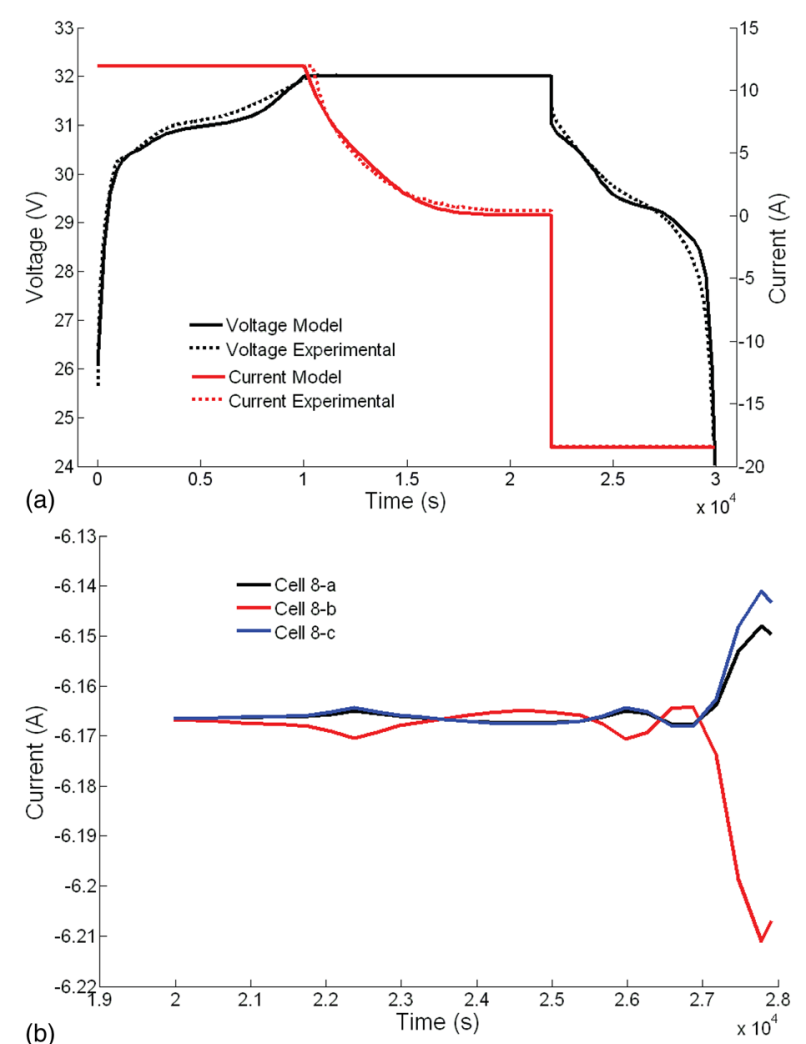

Figure 8. (Color online) The electrical behaviors for battery during a charge/discharge cycle. (a) current and voltage plots for the entire battery pack, (b) current for individual cells in virtual cell 8 in discharge. 
also a technique to maximize the capacity of the battery in practical application, and this battery model provides a mathematical approach to estimate the change in the cell electrode surface SoC due to the self-balancing.

Simulation for charge/discharge cycle.-The battery model was used to simulate a charge/discharge cycle of the battery pack with the following protocol:

(1) Charge the battery pack at 11.9 A to $32 \mathrm{~V}$;

(2) Hold the battery voltage constant at $32 \mathrm{~V}$ until current tapers to $0.358 \mathrm{~A}$;

(3) Discharge the battery at 18.5 A until any virtual cell drops to $3 \mathrm{~V}$.

In this cycling test, the temperature of the cold plate was kept at $15^{\circ} \mathrm{C}$. All the cells were assumed to be connected with identical surface $\mathrm{SoC}$ values, so the self-balancing process can be neglected. The simulated vs experimental voltage-current profiles for battery in the cycle are presented in Fig. 8a. By comparing model predictions with experimental data, the initial surface $\mathrm{SoC}$ values were obtained as $\left.\theta_{p, i}\right|_{t=0}=0.99$ and $\left.\theta_{n, i}\right|_{t=0}=0.01$. In this cycle, the individual cells have small variations in electrical behaviors; for example, in Fig. $8 \mathrm{~b}$, the discharge currents of the three cells in virtual cell 8 are different and the deviation is maximum (about $0.1 \mathrm{~A}$ between highest and lowest) at the end of discharge where the voltage changes very rapidly.

The simulated cell temperature profiles during the cycle were also compared with experimental data and the results are presented in Fig. 9a through 9d. In these comparisons, the specific heat capacity of cell, the contact thermal resistance between different parts (see Table I), and the ohm resistance values which vary between different cells were adjusted. The values for these adjustable parameters are listed in Table III. In the plots of Fig. 9, both the model results and experimental data show that the cell temperature drops at the beginning of constant current charging process and then rises slowly as charging continues; as cell current tapers during the constant voltage charge, cell temperature drops to the cold plate temperature; and when the constant current discharge starts, the cell temperature keeps increasing rapidly all through the discharge process. These phenomena can be explained by analyzing the heat generation mechanism in the energy balance equation. In Eq. 12, the reversible heat $I T\left(\frac{\partial U_{p}^{\theta}}{\partial T}-\frac{\partial U_{n}^{\theta}}{\partial T}\right)$ could be either positive or negative depending on the direction and stage of reaction, while the irreversible heat $I\left[V_{\text {cell }}-\left(U_{p}^{\theta}-U_{n}^{\theta}\right)\right]$ is always positive for both charging and discharging. According to the discussions in Ref. 2, the reversible heat and irreversible are of the same order in magnitude, and they have a joint effect on the cell temperature change. Over most stages of the charge process, the electrochemical reactions are endothermic and the reversible heat is negative, and this strongly cancels the heating effects from the irreversible heat, so the cell temperature either decreases or just increases very slightly. In the discharge process, the electrochemical reactions are reversed to exothermic, so the reversible heat becomes positive and both the reversible and irreversible heat simultaneously drive the cell temperature to increase fast.

As shown in Figs. 9a and 9b, for cells in the each virtual cell (\#3 or \#8, e.g.), the one in the middle (cell 3-b or cell 8-b) is about $1^{\circ} \mathrm{C}$ hotter than those located at edges (cell 3-a \& 3-c, or cell 8-a \& 8-c). The reason is that the vertical boards (b2\&b3, or b4\&b5) are cold boundaries due to the high thermal conductivity and they take the heat away from the edge of the cells.

Simulation for circuit interruption.-Our research interests in battery circuit interruption were motivated by the safety concerns in battery pack design. This battery was designed to work on satellite for 5000-10000 cycles, and the long-time operations at large current
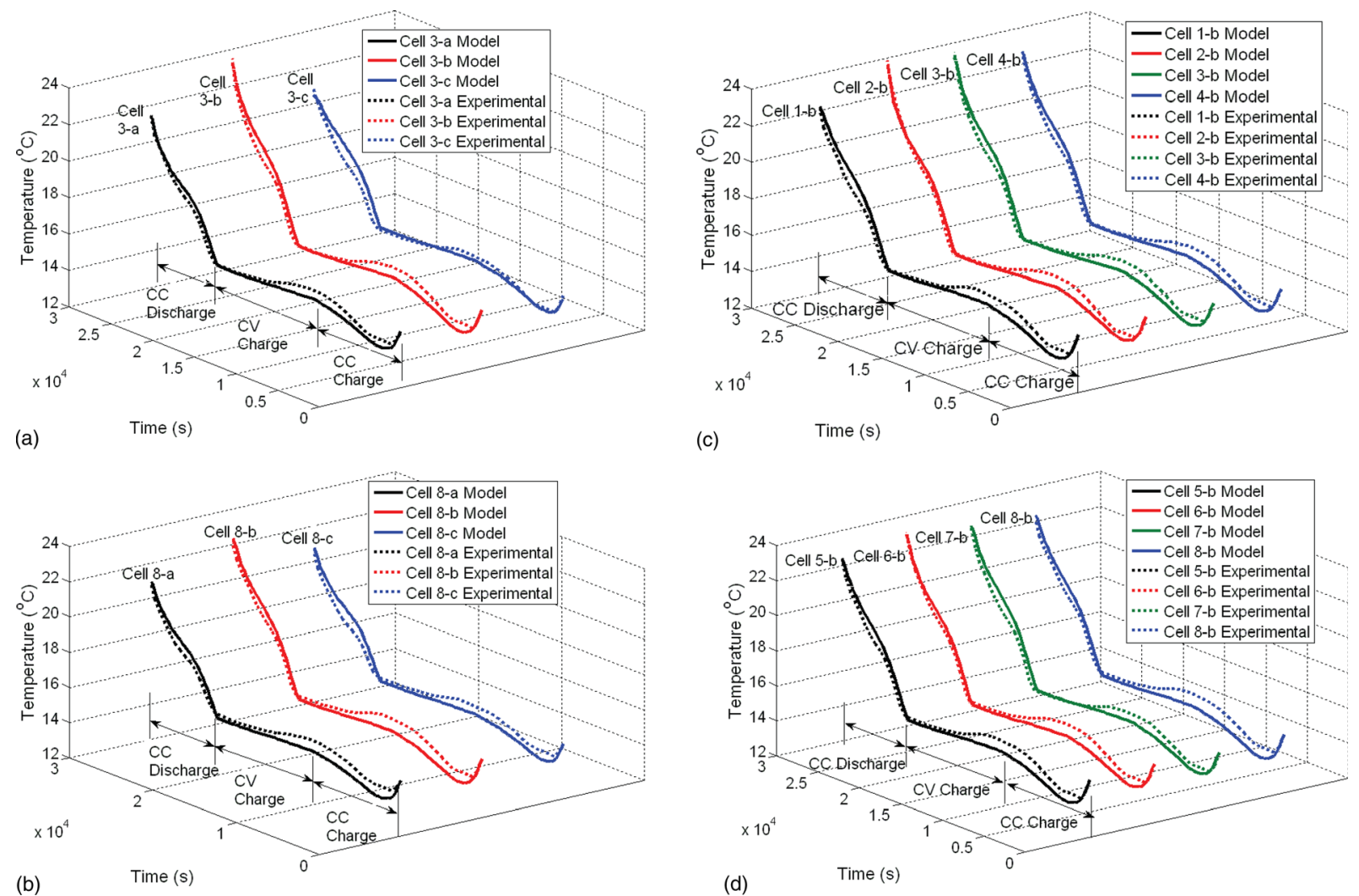

Figure 9. (Color online) Comparison of temperature profiles for different individual cells during the charge/discharge cycle: (a) all three cells in virtual cell 3 , (b) all three cells in virtual cell 8, (c) the center cells in virtual cell 1 through 4, (d) the center cells in virtual cell 5 through 8 . 


\begin{tabular}{|c|c|c|}
\hline Parameter & Value & Unit \\
\hline$R_{h, C V}$ & 5.32 & $(\mathrm{~K} / \mathrm{w})$ \\
\hline$R_{h C H}$ & 5.79 & $(\mathrm{~K} / \mathrm{w})$ \\
\hline$R_{h C C}$ & 10.06 & $(\mathrm{~K} / \mathrm{w})$ \\
\hline$R_{h, V H}$ & 0.30 & $(\mathrm{~K} / \mathrm{w})$ \\
\hline$R_{h . H P}$ & 0.002 & $(\mathrm{~K} / \mathrm{w})$ \\
\hline$R_{\text {cell } 1-a}$ & 0.0105 & $(\Omega)$ \\
\hline$R_{\text {cell }, 1-b}$ & 0.0095 & $(\Omega)$ \\
\hline$R_{\text {cell }, 1-c}$ & 0.0105 & $(\Omega)$ \\
\hline$R_{\text {cell }, 2-a}$ & 0.0105 & $(\Omega)$ \\
\hline$R_{\text {cell }, 2-b}$ & 0.0125 & $(\Omega)$ \\
\hline$R_{\text {cell }, 2-c}$ & 0.0105 & $(\Omega)$ \\
\hline$R_{\text {cell }, 3-a}$ & 0.0120 & $(\Omega)$ \\
\hline$R_{\text {cell }, 3-b}$ & 0.0120 & $(\Omega)$ \\
\hline$R_{\text {cell }, 3-c}$ & 0.0103 & $(\Omega)$ \\
\hline$R_{\text {cell }, 4-a}$ & 0.0105 & $(\Omega)$ \\
\hline$R_{\text {cell }, 4-b}$ & 0.0106 & $(\Omega)$ \\
\hline$R_{\text {cell }, 4-c}$ & 0.0105 & $(\Omega)$ \\
\hline$R_{\text {cell }, 5-a}$ & 0.0105 & $(\Omega)$ \\
\hline$R_{\text {cell }, 5-b}$ & 0.0100 & $(\Omega)$ \\
\hline$R_{\text {cell }, 5-c}$ & 0.0105 & $(\Omega)$ \\
\hline$R_{\text {cell }, 6-a}$ & 0.0105 & $(\Omega)$ \\
\hline$R_{\text {cell }, 6-b}$ & 0.0110 & $(\Omega)$ \\
\hline$R_{\text {cell }, 6-c}$ & 0.0105 & $(\Omega)$ \\
\hline$R_{\text {cell }, 7-a}$ & 0.0105 & $(\Omega)$ \\
\hline$R_{\text {cell }, 7-b}$ & 0.0103 & $(\Omega)$ \\
\hline$R_{\text {cell }, 7-c}$ & 0.0105 & $(\Omega)$ \\
\hline$R_{\text {cell }, 8-a}$ & 0.0100 & $(\Omega)$ \\
\hline$R_{\text {cell. } 8-b}$ & 0.0095 & $(\Omega)$ \\
\hline$R_{\text {cell }, 8-c}$ & 0.0100 & $(\Omega)$ \\
\hline
\end{tabular}

raise the danger of circuit interruption. For example, the wire junctions have the potential to be broken due to the high local resistance caused by corrosion of screws, and this will result in the shutting off of one or more cells (see Fig. 10). The virtual cell with one cell broken has a smaller capacity than others, and this imbalance would cause a performance decrease for the entire battery pack. Our model can be used for discontinuous simulation to check the effects of circuit interruption, so that the battery designers could obtain important information to facilitate protective measures.

Assuming that the wire connection for cell $i$ is interrupted at time $t_{b r}$; for $t<t_{b r}$, the governing equations for the battery are the

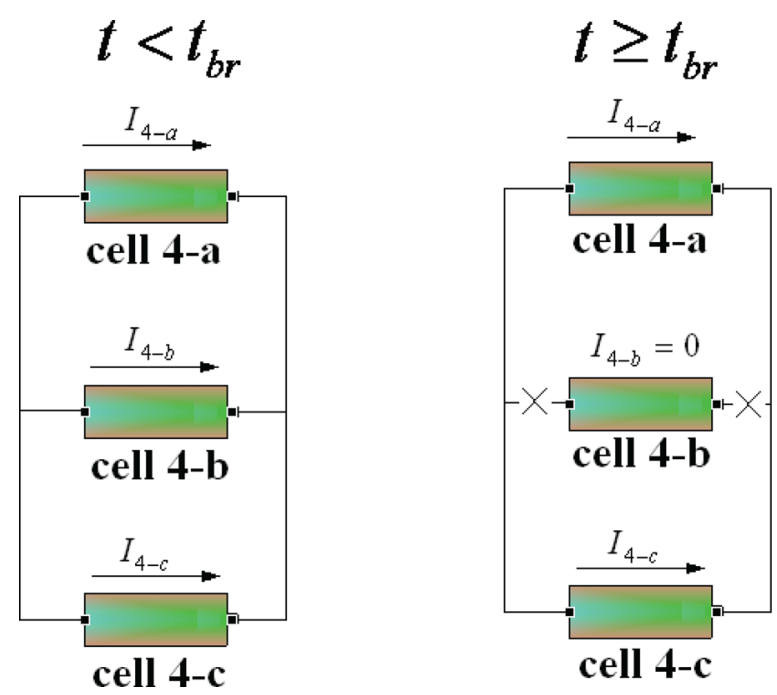

Figure 10. (Color online) The interruption of a virtual cell.
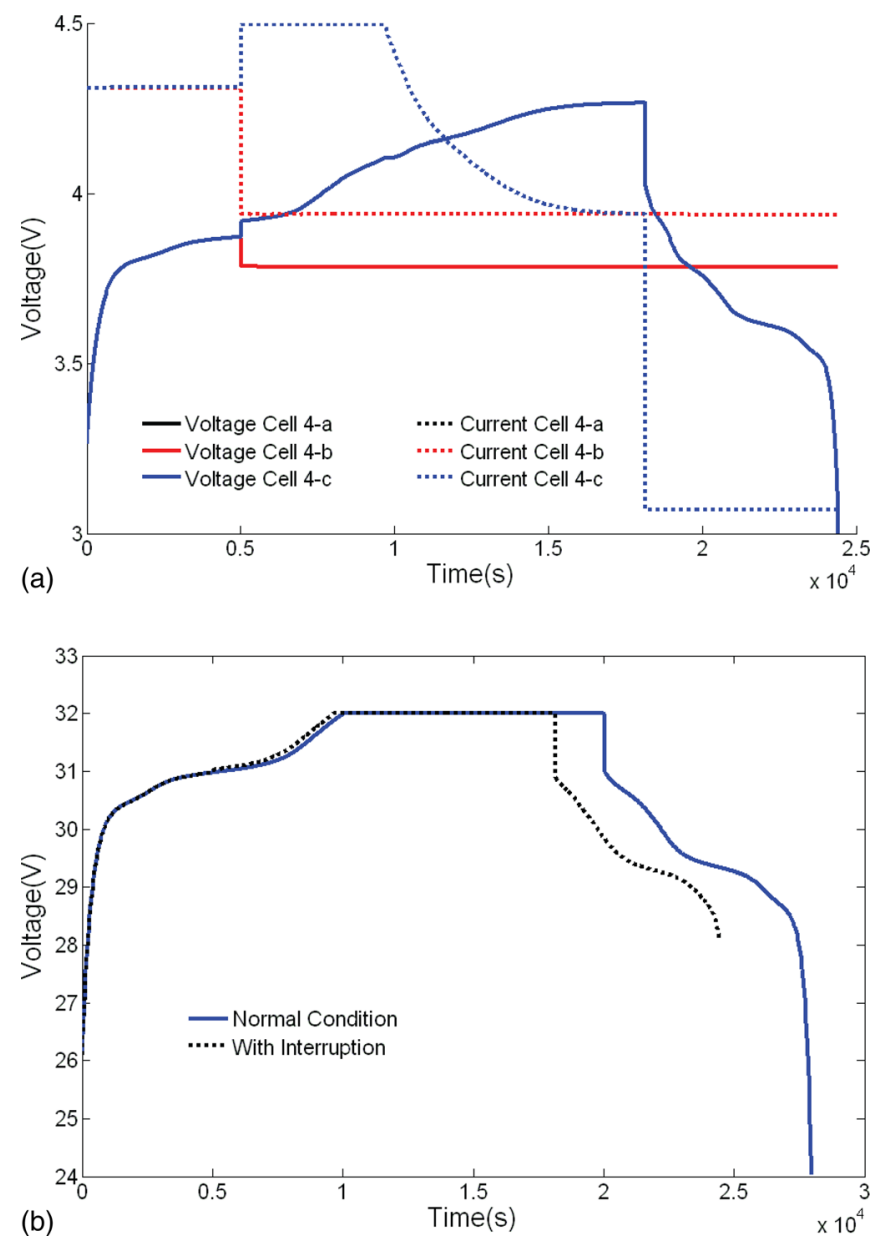

Figure 11. (Color online) The electrical behaviors for battery in the simulation of circuit interruption, (a) current and voltage plots for virtual cell 4 with circuit interruption, (b) voltage for entire battery with/without circuit interruption.

same with those presented previously in the model description section; for $t \geq t_{b r}$, the current passing cell $i$ drops to zero immediately

$$
I_{i}=0 \quad\left(t \geq t_{b r}\right)
$$

and then the voltage constraint described in Eq. 26 for the broken virtual cell becomes

$$
V_{\text {cell } i^{\prime}}=V_{\text {cell } i^{\prime \prime}} \quad\left(t \geq t_{b r}\right)
$$

where $i^{\prime}$ and $i^{\prime \prime}$ are the index of the two other two cells in the same virtual cell with the broken cell $i$. Other governing equations remain the same for $t \geq t_{b r}$.

The model was used to simulate for same charge/discharge cycle as described in the previous section, where cell 4-b was randomly chosen to break at $t_{b r}=5000 \mathrm{~s}$. The voltage-current plots for the cell 4-a through 4-c are presented in Fig. 11a. The broken cell 4- $b$ stays at OCP after time $t_{b r}$, and cell 4- $a$ and 4-c remain working with current jumping by $2.0 \mathrm{~A}$ at time $t_{b r}$. The voltage of the virtual cell jumps by $46 \mathrm{mV}$ at $t_{b r}$ and reaches $4.26 \mathrm{~V}$ at the end of constant voltage charging process, which means other virtual cells are charged below $4 \mathrm{~V}$ because the total voltage for all 8 virtual cells in the series can not exceed $32 \mathrm{~V}$. In such a case, the broken virtual cell is over charged while others are under charged, and this problem will not only result in decrease in battery capacity but also lead to accidents such as combustion.

The comparison of battery pack voltage between cases of circuit interruption and normal use are presented in Fig. 11b. The end-of- 

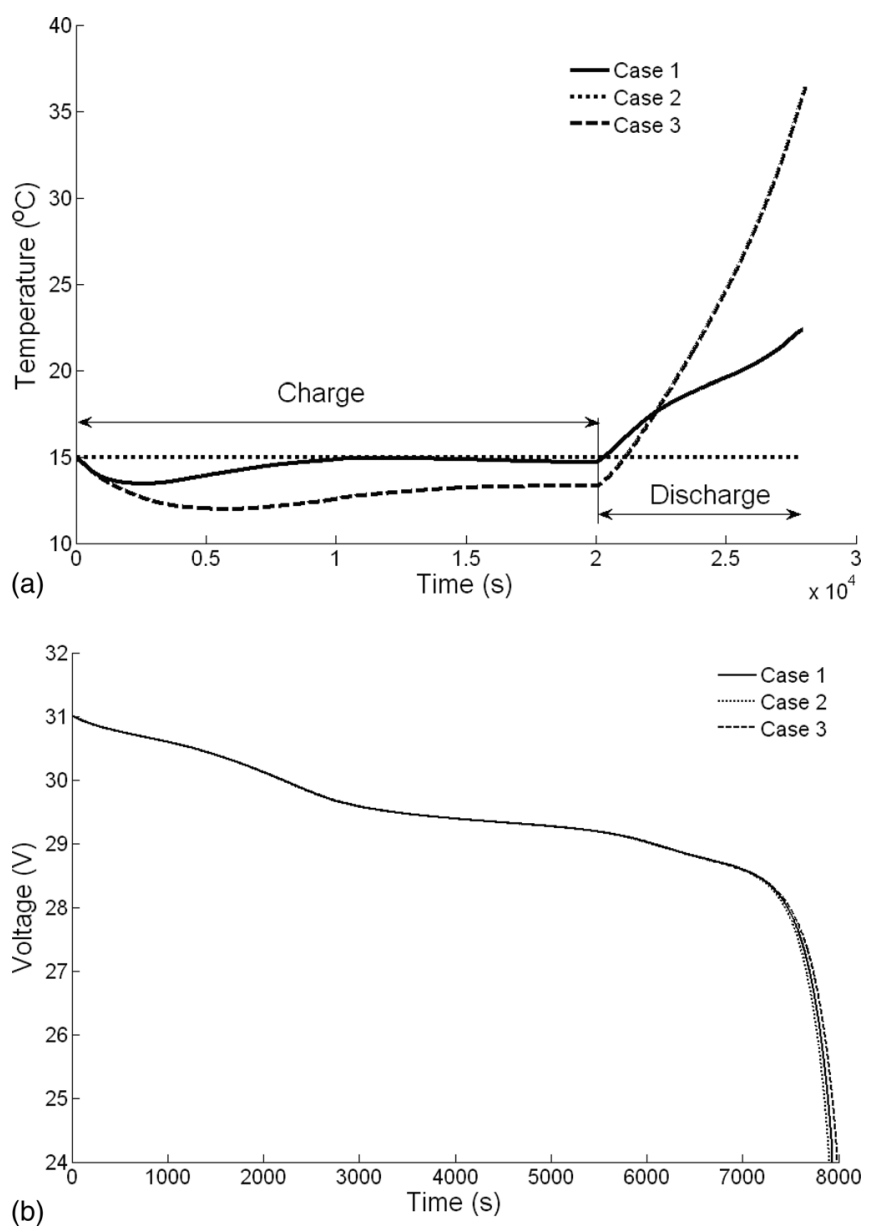

Figure 12. The simulation results for three different thermal conditions, (a) temperature for cell 8-b, (b) voltage for entire battery during discharge.

discharge voltage for battery with interrupted circuit is between 28 and $29 \mathrm{~V}$, higher than that in normal condition. This is because in discharge, the voltage of a broken virtual cell drops to the stop voltage (say $3 \mathrm{~V}$ ) much earlier than others. As discussed above, the battery pack with a broken cell can neither be fully charged nor fully discharged. From Fig. $11 \mathrm{~b}$, the calculated discharge capacity is $40.79 \mathrm{Ah}$ for normal condition and $32.28 \mathrm{Ah}$ for the circuit interruption case, so more than $20 \%$ of the battery capacity is lost if one of the twenty four cells breaks.

Simulation with different thermal conditions.-The thermal effects on the battery performances were studied. The battery pack model was used to simulate charge/discharge cycles with three different thermal condition cases. The cycling protocol is the same as that described in section "Simulation for charge/discharge cycle", and the temperature profiles of Cell 8-b (chosen randomly) are presented in Fig. 12a. The solid curve denotes case 1 where both heat generation in cells and heat transfer between battery and cold plate are considered, the dotted curve denotes the case 2 where the heat generation in cells is neglected, and the dash curve denotes the case 3 where heat transfer between battery and cold plate is neglected. In case 1 , the cell temperature stays at the initial temperature which is same with the cold plate temperature. In case 3, the temperature rise is large due to the thermal insulation between battery and cold plate. The cell temperature profiles of case 2 lies between the curves of case 1 and 3 . As a result of temperature differences in the three cases, the discharge profiles of the battery are slightly different at the end of discharge (Fig. 12b).

\section{Conclusion}

In this work, a thermal model for a battery pack was developed by coupling a single particle model, energy balance, and circuit con- straint, and the model was used for various different simulation work. The simulation results of self-balancing shows that by the parallel connection of cells, the surface SoC difference $\theta_{p}-\theta_{n}$ of cells becomes more uniform, but the deviation in individual electrode surface SoC, $\theta_{p}$ and $\theta_{p}$ of cells is not necessarily reduced. The electrical and thermal predictions of this model for the battery pack during a charge/discharge cycle are consistent with the experimental data. The simulation results for circuit interruption suggests that the breaking of a single cell may cause a significant energy loss for the battery.

\section{Appendix A}

The $U_{j, r e f}^{\theta}$ vs $\theta_{j}$ and $\frac{\partial U_{j}^{\theta}}{\partial T}$ vs $\theta_{j}$ plots for $\mathrm{LiCoO}_{2}$ and MCMB materials are obtained from Ref. 2 and shown in Figs. A-1 and A-2. The fitting functions for these curves are listed below

$$
\begin{aligned}
U_{p}= & 4.04596+\exp \left(-42.30027 \theta_{p}+16.56714\right)-0.04880 \arctan \left(50.01833 \theta_{p}\right. \\
& -26.48897)-0.05447 \arctan \left(18.99678 \theta_{p}-12.32362\right) \\
& -\exp \left(78.24095 \theta_{p}-78.68074\right)
\end{aligned}
$$

$$
\begin{aligned}
U_{n}= & 0.13966+0.68920 \exp \left(-49.20361 \theta_{n}\right)+0.41903 \exp \left(-254.40067 \theta_{n}\right) \\
& -\exp \left(49.97886 \theta_{n}-43.37888\right)-0.028221 \arctan \left(22.52300 \theta_{n}-3.65328\right) \\
& -0.01308 \arctan \left(28.34801 \theta_{n}-13.43960\right)
\end{aligned}
$$

$$
\frac{\partial U_{p}}{\partial T}=\frac{-0.19952+0.92837 \theta_{p}-1.36455 \theta_{p}^{2}+0.61154 \theta_{p}^{3}}{1-5.66148 \theta_{p}+11.47636 \theta_{p}^{2}-9.82431 \theta_{p}^{3}+3.04876 \theta_{p}^{4}}
$$

$$
\frac{\partial U_{n}}{\partial T}=\frac{\begin{array}{c}
\left(0.00527+3.29927 \theta_{\mathrm{n}}-91.79326 \theta_{\mathrm{n}}^{2}+1004.91101 \theta_{\mathrm{n}}^{3}-5812.27813 \theta_{\mathrm{n}}^{4}\right. \\
\left.+19329.75490 \theta_{\mathrm{n}}^{5}-37147.89470 \theta_{\mathrm{n}}^{6}+38379.18127 \theta_{\mathrm{n}}^{7}-16515.05308 \theta_{\mathrm{n}}^{8}\right)
\end{array}}{\left(\begin{array}{l}
1-48.09287 \theta_{\mathrm{n}}+1017.23480 \theta_{\mathrm{n}}^{2}-10481.80419 \theta_{\mathrm{n}}^{3}+59431.30001 \theta_{\mathrm{n}}^{4} \\
\left.-195881.64880 \theta_{\mathrm{n}}^{5}+374577.31520 \theta_{\mathrm{n}}^{6}-385821.16070 \theta_{\mathrm{n}}^{7}+165705.85970 \theta_{\mathrm{n}}^{8}\right)
\end{array}\right.}
$$
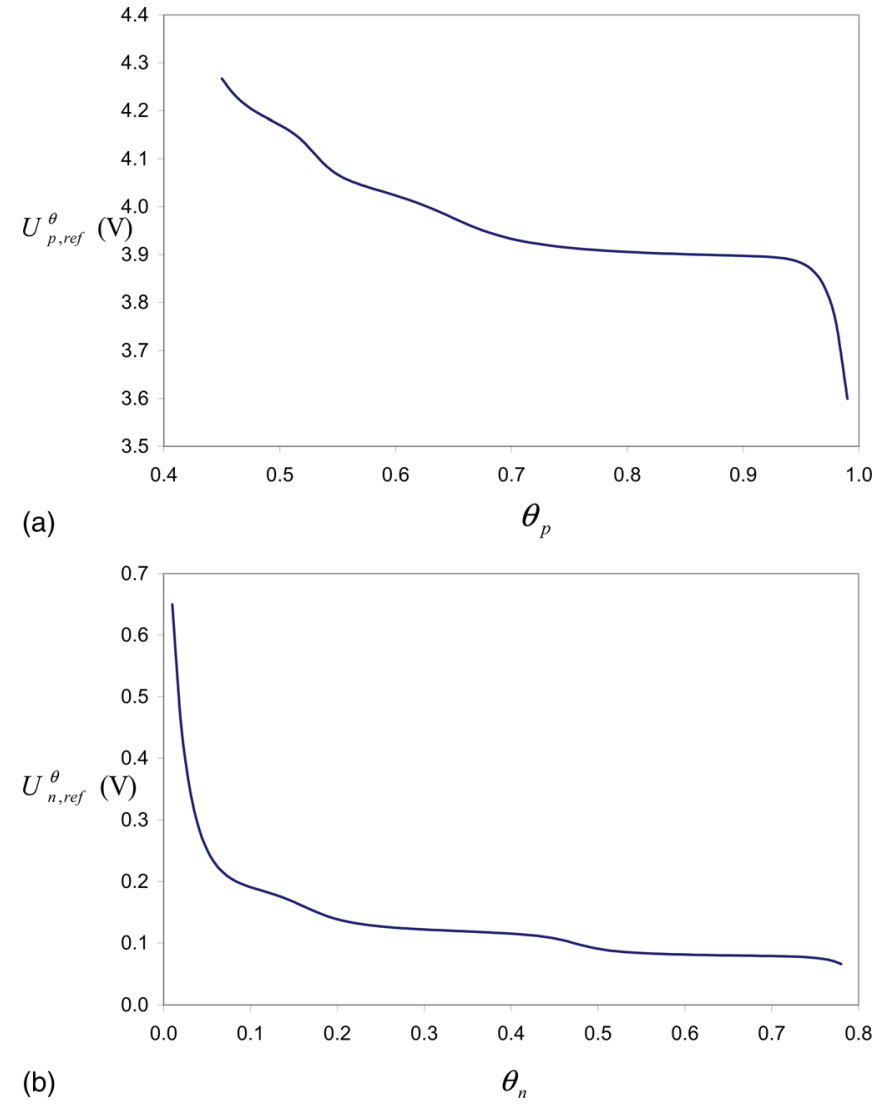

Figure A-1. (Color online) The open circuit potential profiles for (a) positive and (b) negative electrodes. 


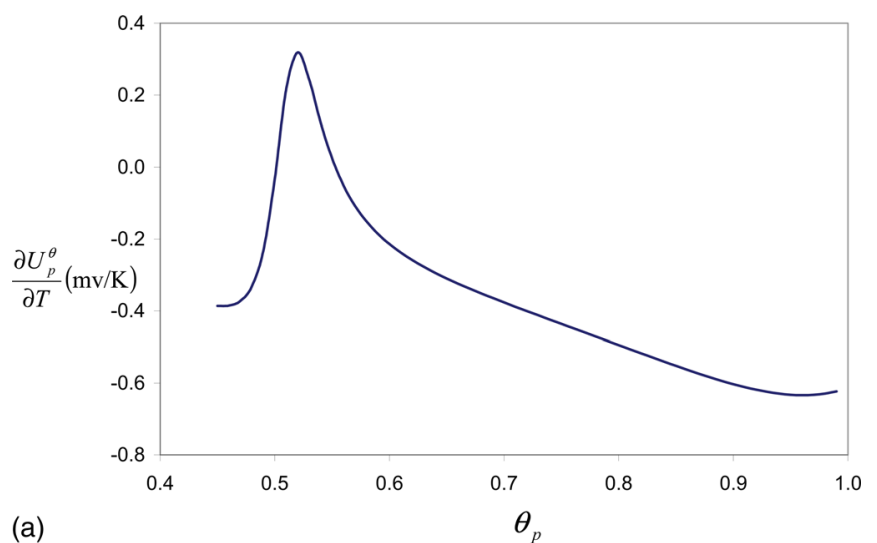

(a)

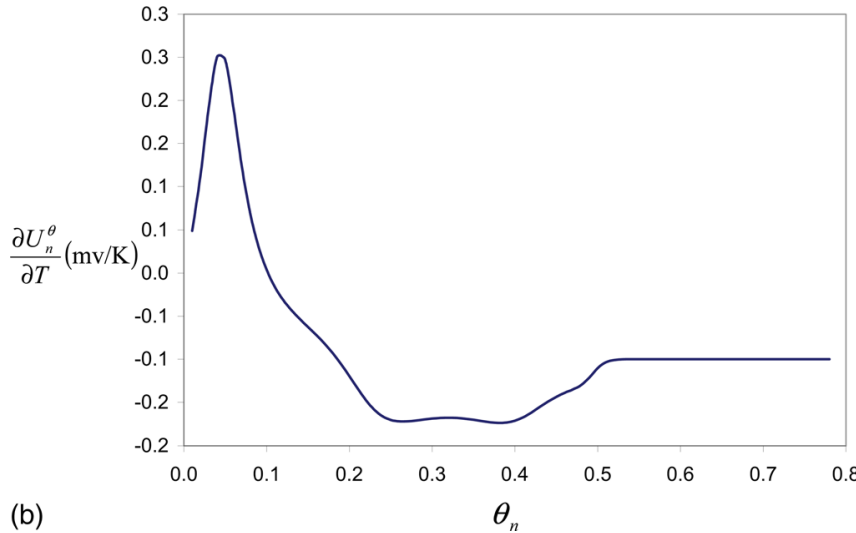

Figure A-2. (Color online) The entropy change coefficient profiles for (a) positive and (b) negative electrodes.

\section{Appendix B}

As discussed previously, the cell OCV depends on the surface SoC of individual electrodes. If cells with identical OCV values are connected in parallel, the correlation shown in Eq. 26 is obviously satisfied. However, the OCV of cells to be assembled into a virtual cell are not necessarily exactly the same. As cells with non-identical OCV are hooked up in parallel (see Fig. B-1), a mutual charge/discharge process will occur between these cells. In such a process, the cells with lower voltage will be charged and those with higher voltage will be discharged, and the overpotential caused from the charge/discharge would balance the difference in cell OCV. The electrode surface SoC will change accordingly as lithium is intercalated/deintercalated into/from particles during charge/discharge. When the mutual charge/discharge process is finished, the current of each cell drops to zero and the circuit reaches to a steady state in which all the cells are of the same OCV. The process described above is called the self-balancing of a battery, and the final electrode surface $\mathrm{SoC}$ values after self-balancing are used as consistent initial conditions for the following procedure of simulation.
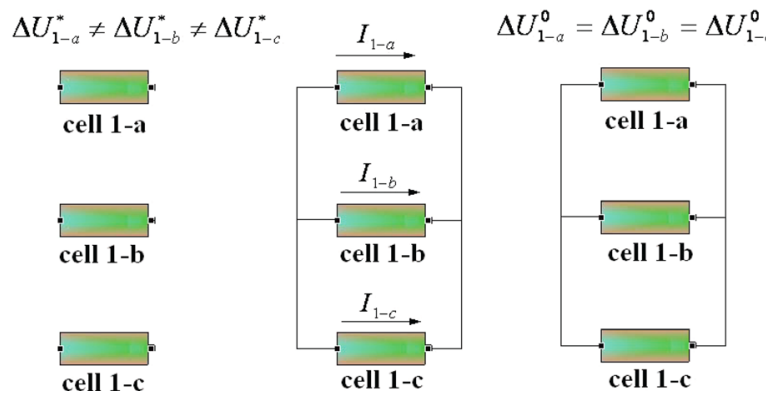

Figure B-1. (Color online) The self-balancing process of battery.
The work of Ref. 18 has shown that the individual electrode surface SoC values for an unconnected single cell can be estimated. If these single cells with known surface SoC are connected to build a battery, the surface SoC change for each cell due to the self-balancing can be calculated with our battery model.

Take the first virtual cell (including cell $1-a, 1-b$, and 1-c) as an example. The average particle and surface lithium concentration for the unconnected cells are known as $\bar{c}_{1, j, i}^{*}$ and $c_{s, j, i}^{*}$ respectively (where $j=p, n ; i=1-a, 1-b$, and $1-c$ ). There is no current in each cell before the connection, so according to Eqs. 2, 9, and 10, we can find that the average particle lithium concentration equals to the surface lithium concentration at open circuit

$$
c_{s, j, i}^{*}=\bar{c}_{1, j, i}^{*}
$$

The $c_{s, j, i}^{*}$ values can be calculated from the surface SoC of unconnected cells. The particle average and surface lithium concentration for the cells after the self-balancing are $c_{s, j, i}^{0}$ and $\bar{c}_{1, j, i}^{0}$. The current of each cell tapers to zero after self-balancing, so we can find a similar correlation to Eq. B-1

$$
c_{s, j, i}^{0}=\bar{c}_{1, j, i}^{0}
$$

According to the definition of surface SoC in Eq. 3, the state of charge for self-balanced cells is expressed as

$$
\theta_{j, i}^{0}=\bar{c}_{1, j, i}^{0} / c_{1, j}^{\max }=c_{s, j, i}^{0} / c_{1, j}^{\max }
$$

Assuming that the duration of self-balancing process is long enough, so that the heat generated by the charge/discharge is completely transferred to the surroundings and the temperature of the cells equals to the ambient temperature $T_{a m b}$. According to Eq. 25 , the electrode OCP of cells after self-balancing $U_{j, i}^{\theta, 0}$ can be expressed as

$$
U_{j, i}^{\theta, 0}=\left.U_{j, i, r e f}^{\theta}\right|_{\theta_{j, i}^{0}}+\left.\frac{\partial U_{j}^{\theta}}{\partial T}\right|_{\theta_{j, i}^{0}}\left(T_{a m b}-T_{r e f}\right)
$$

As shown in Eqs. B-3 and B-4, $U_{j, i}^{\theta, 0}$ is a function of $c_{s, j, i}^{0}$. According to Eq. 11, the OCV of cells after self-balancing can be expressed as

$$
\Delta U_{i}^{0}=\left.V_{\text {cell }}\right|_{I=0}=U_{p, i}^{\theta, 0}-U_{n, i}^{\theta, 0}
$$

As cell $1-a, 1-b$ and $1-c$ are connected in parallel, Eq. 26 needs to be satisfied at open circuit

$$
\Delta U_{1-a}^{0}=\Delta U_{1-b}^{0}=\Delta U_{1-c}^{0}
$$

To integrate Eqs. 1 and 2 with time from the start $\left(t^{*}\right)$ to the end $(t 0)$ of self-balancing, one can derive

$$
\frac{3}{F} \int_{t^{*}}^{t^{0}} J_{j, i} d t=-A_{j} R_{j}\left(c_{s, j, i}^{0}-c_{s, j, i}^{*}\right)
$$

From Eqs. 9 and 10, we can obtain

$$
J_{p, i}+J_{n, i}=0
$$

Write Eq. B-7 respectively for $j=p$ and $j=n$, add up the two equations, then apply Eq. B-8 to get

$$
A_{p} R_{p}\left(c_{s, p, i}^{0}-c_{s, p, i}^{*}\right)+A_{n} R_{n}\left(c_{s, n, i}^{0}-c_{s, n, i}^{*}\right)=0
$$

From Eqs. 9, 10, and 26, we also find the correlation of reaction current between different cells in parallel

$$
\sum_{i} J_{j, i}=0
$$

Apply Eq. B-10 to B-7 to obtain

$$
\sum_{i} A_{j} R_{j}\left(c_{s, j, i}^{0}-c_{s, j, i}^{*}\right)=0
$$

Three linear equations can be obtained by writing Eq. B-9, respectively, for $i=1-a, 1-$ $b$, and 1-c, Eq. B-11 provides another linear equation, and there are two nonlinear equations included in Eq. B-6. As discussed above, six unknowns $\left(c_{s, j, i}^{0}\right.$ where $j=p$ and $n$ and $i=1-a, 1-b$, and $1-c)$ can be determined by the equation system for self-balancing.

\section{List of Symbols}

$A_{j} \quad$ surface area of electrode $j, \mathrm{~m}^{2}$

$\bar{c}_{1, j} \quad$ average particle concentration of lithium of electrode $j, \mathrm{~mol} \cdot \mathrm{m}^{-3}$ 
$c_{1, j}^{\max }$ maximum lithium concentration in the particle of electrode $j$, $\mathrm{mol} \cdot \mathrm{m}^{-3}$

$c_{2}$ electrolyte concentration in the solution phase, $\mathrm{mol} \cdot \mathrm{m}^{-3}$

$c_{s, j} \quad$ concentration of lithium at the particle surface of electrode $j$, $\mathrm{mol} \cdot \mathrm{m}^{-3}$

$C_{p} \quad$ specific heat capacity of cell, $\mathrm{J} \cdot \mathrm{kg}^{-1} \cdot \mathrm{K}^{-1}$

$D_{1, j}$ diffusion coefficient of lithium inside the particle of electrode $j$, $\mathrm{m}^{2} / \mathrm{s}$

$D_{1, j, r e f}$ diffusion coefficient of lithium inside the particle of electrode $j$ at reference temperature, $\mathrm{m}^{2} / \mathrm{s}$

$E a_{d, j} \quad$ activation energy for the lithium diffusion in the particle of electrode $j, \mathrm{~J} / \mathrm{mol}$

$E a_{r, j}$ activation energy for the electrochemical reaction of electrode $j$, $\mathrm{J} / \mathrm{mol}$

$F \quad$ Faraday's constant, $\mathrm{C} / \mathrm{mol}$

$I$ applied current of cell, A

$I_{a p p} \quad$ applied current of battery pack, A

$J j \quad$ current for intercalation reaction of electrode $j, \mathrm{~A}$

$k_{j}$ rate constant for electrochemical reaction of electrode $j$, $\mathrm{m}^{2.5} \cdot \mathrm{mol}^{-0.5} \cdot \mathrm{s}^{-1}$

$k_{j, r e f}$ rate constant for electrochemical reaction of electrode $j$ at temperature, $\mathrm{m}^{2.5} \cdot \mathrm{mol}^{-0.5} \cdot \mathrm{s}^{-1}$

$N_{k}$ heat flux on the $k$ th surface of cell, W. $\mathrm{m}^{-2}$

$q$ heat flow rate from single cell to surroundings, W

$q^{\prime}$ heat flow rate between a board and its surroundings, W

$R$ universal gas constant, $\mathrm{J} \cdot \mathrm{mol}^{-1} \cdot \mathrm{K}^{-1}$

$R_{\text {cell }} \quad$ ohm resistance of cell, $\Omega$

$R_{h, C C}$ thermal resistance between different cells, K/W

$R_{h, C H}$ thermal resistance between cell and horizontal board, K/W

$R_{h, C V}$ thermal resistance between cell and vertical board, K/W

$R_{h, H P}$ thermal resistance between horizontal board and cold plate, K/W

$R_{h, V H}$ thermal resistance between cell and vertical and horizontal board, $\mathrm{K} / \mathrm{W}$

$R_{j} \quad$ particle radius of electrode $j, \mathrm{~m}$

$S_{k} \quad$ area of the $k$ th surface of cell, $\mathrm{m}^{2}$

$t$ Time, s

$T$ temperature, ${ }^{\circ} \mathrm{C}$

$T_{\text {ref }}$ reference temperature, ${ }^{\circ} \mathrm{C}$

$U_{j}^{\theta} \quad$ open circuit potential (OCP) of electrode $j, \mathrm{~V}$

$U_{j, r e f}^{\theta} \quad$ open circuit potential (OCP) of electrode $j$ at reference temperature, $\mathrm{V}$

$\Delta U$ open circuit voltage of cell, $\mathrm{V}$ $v$ volume of cell, $\mathrm{m}^{3}$

$V_{\text {app }} \quad$ applied voltage of battery pack, $\mathrm{V}$

$V_{\text {cell }}$ cell voltage, $\mathrm{V}$

Greek

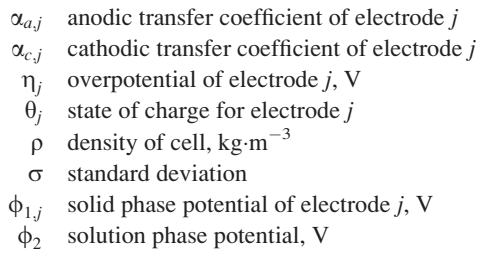

\section{References}

1. S. Browna, K. Ogawab, Y.Kumeuchic, S. Enomotoc, M. Unod, H. Saitod, Y. Soned, D. Abrahame, and G. Lindbergha, J. Power Sources, 1851444 (2008).

2. M. Guo, G. Sikha, and R. E. White, J. Electrochem. Soc., 158, A122 (2011).

3. C. R. Pals and J. Newman, J. Electrochem. Soc., 142, 3274 (1995).

4. C. R. Pals and J. Newman, J. Electrochem. Soc., 142, 3282 (1995).

5. V. Srinivasan and C. Y. Wang, J. Electrochem. Soc., 150, A98 (2003).

6. K. Kumaresan, G. Sikha, and R. E. White, J. Electrochem. Soc., 155, A164 (2008).

7. S. Santhanagopalan, Q. Guo, P. Ramadass, and R. E. White, J. Power Sources, 156, 620 (2006)

8. G. Ning and B. N. Popov, J. Electrochem. Soc., 151, A1584 (2004).

9. T. F. Fuller, M. Doyle, and J. Newman, J. Electrochem. Soc., 141, 1 (1994).

10. D. Bernardi, E. Pawlikowski, and J. Newman, J. Electrochem. Soc., 123, 5 (1985).

11. L. Rao and J. Newman, J. Electrochem. Soc., 144, 2697 (1997).

12. G. Botte, B. Johnson, and R. E. White, J. Electrochem. Soc., 146, 914 (1999).

13. K. Nakamura, H. Ohnoa, K. Okamurac, Y. Michihiroa, I. Nakabayashib, and T. Kanashiro, Solid States Ionics, 135, 143 (2000).

14. O. Egorkina and A. Skundin, J. Solid State Electrochem., 2, 216 (1998)

15. T. Kulova, A. Skundin, E. Nizhnikovskii, and A. Fesenko, Russ. J. Electrochem., 42, 259 (2006).

16. H. Zheng, J. Qin, Y. Zhao, T. Abe, and Z. Ogumi, Solid States Ionics, 176, 2219 (2005)

17. W. B. Gu and C. Y. Wang, ECS Proceedings, 99-25, 748 (2000).

18. S. Santhanagopalan, Q. Guo, and R. E. White, J. Power Sources, 154, A198 (2007). 